\title{
Habitat richness and tree species richness of roundabouts: effects on site selection and the prevalence of arboreal caterpillars
}

by Goodwin, C., Keep, B. and Leather, S.R.

Copyright, Publisher and Additional Information: This is the author accepted manuscript. The final published version (version of record) is available online via Springer Please refer to any applicable terms of use of the publisher.

DOI: $10.1007 / s 11252-017-0644-7$ 


\title{
Habitat richness and tree species richness of roundabouts: effects on site selection and the prevalence of arboreal caterpillars
}

\author{
Cecily Goodwin ${ }^{1,2}$ Bruce Keep ${ }^{1}$ Simon R Leather 1,3
}

${ }^{1}$ Department of Life Sciences, Imperial College London, Silwood Park, Ascot SL5 7PY UK, ${ }^{2}$ Environment \& Sustainability Unity, University of Exeter, Penryn Campus, Penryn, Cornwall TR10 9FE UK ${ }^{3}$ Crop \& Environment Sciences, Harper Adams University, Edgmond, Newport TF10 8 NB UK

\begin{abstract}
This study examined the relationship between the habitat and tree species richness of roundabouts and the abundance and species richness of tree-dwelling caterpillars, and thus the potential of urban roundabouts to support breeding populations. Total tree species number on sites was related to an increase in caterpillar abundance and a greater number of habitats was associated with a higher number of caterpillar species. An increase in the total number of trees was not correlated with a greater abundance of tree-feeding Lepidoptera; nor were native trees found to support proportionally more caterpillar species than all tree species, including introduced. This could be due to differences in species accumulation, the prevalence of generalist species or a statistical sampling effect. The occupancy and average abundance of caterpillar species was generally low, which does not support the theory that Lepidoptera in urban areas tend towards monodominance. It may, however, represent the presence of 'accidental' species on roundabouts. Habitat management and planting to increase tree species diversity and density on roundabouts has the potential to increase the species diversity and abundance of arboreal Lepidoptera, and increase abundance of butterfly and moth urban populations.
\end{abstract}

Keywords Lepidoptera, roundabouts, habitat diversity, arboreal caterpillars, management, tree density

\section{Introduction}

Urbanisation is increasing rapidly in many parts of the world and in the UK, one tenth of the land area has now been urbanised (Fuller et al., 2002). In response, the field of urban ecology has grown in recent years, reflecting an interest in utilising expanding urban areas for the conservation of biodiversity (Niemela 1999; Goddard et al., 2009; Evans et al., 2009). Additionally, urban green space and increased biodiversity can improve the well-being of people and communities (Maller et al. 2005; Angold et al., 2006: Jones \& Leather 2012).

Lepidoptera are important in the pollination of urban plants, and plants in surrounding areas (Eremeeva \& Sushchev, 2004). Butterflies are also highly aesthetically valued by people and thus increased species number and abundance could improve urban environments for city residents (Di Mauro, 2007). They also constitute an important food resource for many forest bird species, and increased abundance, particularly of caterpillars, could have positive effects on bird species populations (Tremblay, 2005). Blair (1999) has proposed the use of butterfly species as indicators of urban biodiversity as their abundances correlate highly with those of birds. Lepidoptera are also 
highly dependent on host plant species and so could be used as a surrogate for plant diversity and it is likely that responses would be sensitive enough to provide warnings of change (Blair \& Launer, 1995).

Urbanization is generally associated with species loss due to loss of habitat and fragmentation (Faeth \& Kane, 1978; Evans et al., 2009) and this pattern has been observed for Lepidopteran species (Blair \& Launer, 1995; Denys \& Schmidt, 1998). Despite these effects, many studies have however, found that urban areas can support high levels of insect diversity (Zapparoli, 1997; Helden \& Leather, 2005; Leather \& Helden, 2005). Studies have also found that there is no difference in Lepidoptera species richness between rural and urban areas with similar levels of fragmentation (Rickman \& Connor, 2003). In addition, roadside verges in urban areas have been shown to support large numbers of butterfly and moth species. Saarinen et al. (2005) found that roadside grass verges harboured 53 species of butterfly and 46 species of diurnal moth, and thus should not be underappreciated as potential habitat.

The study of Lepidoptera in urban ecology has primarily focused on either the rural-urban gradient in diversity and abundance (Blair, 1999; Hardy \& Dennis, 1999; Di Mauro et al., 2007) or in comparisons between rural and urban patches (Wolda et al., 1994; Rickman \& Connor, 2003). Information is lacking, however, on habitat use and host-plant interactions of Lepidoptera in urban areas (Guilano et al., 2004). Studies have also mainly looked at the occurrence of adult Lepidoptera and the use of urban green space in providing connectivity between natural habitats (Vickery, 1995; Whitmore et al, 2002). There has been relatively little attention paid to the occurrence of caterpillars in urban areas, and thus their potential to support breeding populations of Lepidoptera (but see Rickman \& Connor, 2003). In this paper we examine the effect of habitat richness, tree abundance and tree species number on the abundance and species number of caterpillars on roundabouts in Bracknell, Southeast England, and thus infer information on the site selection of adult female Lepidoptera and the potential use of urban roundabouts as breeding habitat for tree dwelling Lepidoptera species.

\section{Material and methods}

\section{The sites}

The data were collected at 18 roundabout sites at various locations in Bracknell, Southeast England, between latitude $51^{\circ} 23^{\prime}$ and $51^{\circ} 26^{\circ} \mathrm{N}$ and longitude $0^{\circ} 43^{\prime}$ and $0^{\circ} 47^{\circ} \mathrm{W}$ (Helden \& Leather, 2004). Data for one or more of the site variables could not be collected for sites 1, 9, 13 and 16 for various reasons, and so these were excluded from the final analysis. The grid references of the remaining sites are as described in table 1 .

\section{Habitat}

Each site was assessed for presence/absence of habitat types. These included: short grass (mown once a week); coarse grass (unmown); tall grass (mown once a month); low scrub; tall scrub; small trees; tall trees; flowerbed; water body; lake and shore. The number of habitats in each site was 
summed to give a figure for habitat richness. The classification of habitats was somewhat subjective and defined in comparison to other sites.

\section{Caterpillar diversity and abundance}

Each site was divided into four equal sections. In order to control for the variable sampling effort, which arose from having different numbers of tree species on roundabouts, a single tree was randomly selected for sampling from each section. One branch at head height, on the tree from each direction, North, South, East and West, was randomly selected and sampled by vigorous beating for 10 seconds. The collected caterpillars were then placed in a cage labelled with the site number and the date after initial descriptions of each caterpillar was made. The data were collected weekly, over 6 weeks in June, 2006.

The caterpillars were then taken to the field station for identification. The early instar caterpillars were raised, with the appropriate food plant, for a number of weeks in order to increase their size and aid identification; although some did not reach adulthood and were not included in the final data frame. The later instars often reached pupal stages and adulthood, allowing identification of the butterfly or moth and verification of the caterpillar identification. There were specimens, however, that reached pupal stages prior to identification. These were identified as morphological species using notes on characteristics and comparison with other species. The morphological species were specific to one site and did not occur across sites. Identification of caterpillar larvae of most British Lepidoptera can be established with reasonable confidence using size, colour and markings, and choice of food plant (Porter, 1997). The caterpillar species were identified using: Chinery (1976); Carter \& Hargreaves (1986); Porter (1997); Tolman \& Lewington (1997) and Skinner (2000).

\section{Tree species richness and abundance}

Helden and Leather (2004) was used to establish the location and species of trees accessible to insect sampling, with the exception of sites 7 and 11 where there were large wooded areas, and for which sampling was done on trees bordering grasslands to allow comparison with other sites. Native tree species were classed as those that had been continuously present in Britain since the time of the formation of the English Channel (Mitchell \& Wilkinson, 1988).

\section{Statistical analyses}

All statistical analyses were carried out in the $\mathrm{R}$ statistical package (version 2.12.0) (Ihaka \& Gentlemen, 1996). Generalised linear regression models were used to assess caterpillar-habitat characteristics.

As counts of caterpillars and caterpillar species were taken from the same number of trees from each roundabout these numbers were comparable.

The effects of area, total and native tree species richness and abundance and habitat number were examined in relation to caterpillar species richness and abundance. As area was included in the model this controlled for the confounding effects of different sized roundabouts having more trees. Area was logged due to a large range in roundabout areas. 
A generalised linear model with a Poisson error structure was run to look at the effect of these roundabout characteristics on caterpillar species richness and a similar one was run to look at the effects of these factors on caterpillar abundance. Terms were removed from the model via backwards stepwise deletion and the minimal model was used to assess the amount of deviance explained with the term compared to the model without the term. Area was always included in the model.

\section{Results}

A total of 64 identified and morphological species were found across sites, and a total of 79 individual caterpillars (table 1). The number of caterpillar species sampled ranged from $1-11$ across the sites and total abundance of caterpillars ranged from 1-13. The density was calculated using total abundance and area and this ranged from <0.0001 - 0.006 (table 1). The occupancy and abundance data was also collected for each identified (SI 1) and morphological caterpillar (SI 2) species. Two fifths of the species found were identified to species name; the other specimens for which this was not possible were allocated a morphological species name. The occupancy was generally low at $5.6 \%$, reflecting the fact that individual species were generally only present on one site. The total abundance and average abundance were also both low and each species generally had a very limited abundance range. 135 tree species were recorded in total, of which 55 were native.

Of the 1053 tree specimens recorded, 657 of these were identified as a native species. Across sites, tree species richness ranged from 2-32 and abundance ranged widely from 3-395. There were 4 sites which contained no native tree species.

The number of trees on roundabouts did not affect the number of caterpillars $\left(\chi^{2}{ }_{1}=0.02, \mathrm{p}=0.9\right)$; similarly the number of native trees did not affect abundance $\left(\chi^{2}{ }_{1}=2.7, p=0.1\right)$. There was no relationship between roundabout area $\left(\chi^{2}{ }_{1}=1.63, \mathrm{p}=0.2\right)$ or its habitat richness on the number of caterpillars sampled from single species of trees on roundabouts $\left(\chi^{2}{ }_{1}=0.9, p=0.3\right)$. The abundance of caterpillars, did however, increase, with the number of tree species on roundabouts $\left(\chi^{2}{ }_{1}=12.5\right.$, $\mathrm{p}<0.001$ : Figure 1).

The number of caterpillar species was unaffected by the total number of trees $\left(\chi^{2}{ }_{1}=0, p=0.998\right)$; the number of native trees $\left(\chi_{1}^{2}=0, \mathrm{p}=0.998\right)$, or the number of tree species on the roundabout when controlling for habitat richness $\left(\chi_{1}^{2}=2.2, \mathrm{p}=0.14\right)$. Nor did the area of a roundabout affect the number of species found $\left(\chi_{1}^{2}=0.7, p=0.4\right)$, but habitat richness was positively correlated with the number of caterpillar species present $\left(\chi^{2}{ }_{1}=18.6, \mathrm{p}=<0.001\right.$; Figure 2$)$.

\section{Discussion}

Increased habitat richness was shown to increase the species richness of caterpillars (Figure 2). This suggests that greater habitat richness leads to greater availability of niches; a reason put forward to explain the species-area relationship (Arrhenius, 1929). This relationship has also been discovered, for arboreal Hemiptera, on the same roundabout sites by Helden \& Leather (2004). Habitat richness in itself, however, was more influential than area on the species richness of caterpillars and so differences in habitat richness are most likely to explain species-area relationships. Different species 
of Lepidoptera require different habitat types: Saarinen et al. (2005) found that butterflies most depended on the abundance of nectar sources and diurnal moths require areas of shade in roadside verges. Additionally, thermal considerations and microclimatic variation are important for butterfly species (Scheffers et al., 2014), and these microclimatic effects can mediate the effects of urbanisation (Kaiser et al., 2016). Therefore, with increased habitat richness it is more likely that the habitat and microhabitat requirements of more species are met.

Increased habitat heterogeneity will also increase the probability that sites will contain appropriate habitats for the adults of arboreal Lepidoptera, influencing their site selection and increasing the oviposition of eggs onto trees on that site. Topography and vegetation diversity, vegetation quality and the presence of water sources have been found to be most correlated with increased numbers of butterfly species in urban fragments (Brown \& Freitas, 2002; Di Mauro, 2007; Ockinger et al., 2009). Saarinen et al. (2005) found that the number of butterfly species present on roadside verges was most influenced by the availability of nectar sources. Thus increased habitat types are more likely to encompass more of these features, attracting more adult individuals and species and increasing caterpillar abundance and species richness. As Ries et al. (2001) highlighted, for an area to truly add habitat for a species, the habitat must provide resources for all stages of development or be near to appropriate resources.

Caterpillar abundance was also significantly correlated with tree species richness. This effect is independent of, and stronger than, that of area. When considering specialist species, this response is most likely due to the fact that increased tree species richness will increase the specialist Lepidoptera species associated with each tree species (Leather, 1991). In addition, with increased tree species on a site, it is more likely that an immigrating adult Lepidoptera will encounter an appropriate host tree. Sampling was conducted on four trees on each site in each visit and the identity of these trees changed on each visit. So while some reflection of the caterpillar assemblages of multiple tree species on the roundabout is likely to be captured, it may not fully represent the range of specialist species. In the case of generalist species, increased tree species richness will increase the availability of different resources. According to work by Van Dyck et al. (2009) and Takami et al. (2004) generalists do better in urban settings as they are able to exploit the different vegetation types found there (Van Dyck et al. 2009; Takami et al. 2009). Consequently, this response may be more attributable to generalist species. Hardy \& Dennis (1999), however, has highlighted the importance of small patches of host plants in urban areas in allowing populations of specialist Lepidoptera species to persist.

The fact that site area or the number of trees do not effect caterpillar abundance or species richness could be because the related, but more influential, effects of habitat richness and tree species number explain more of the variation in the caterpillar assemblage. While this is captured in the models by including all terms together, a larger sample size might also reveal a significant effect of the area of the site, or of the total number of trees.

Caterpillar species richness and abundance do not increase in response to the abundance or the number of species of native tree. This was also found in Kelly and Southwood's (1999) study of insects associated with trees. They suggested that this effect could be due to the fact that there were fewer native tree species at smaller abundances, producing a less significant statistical effect. 
Alternatively, it could be due to differences between native and introduced tree species in the changing proportions of generalists and specialists involved in insect species accumulation (Kelly \& Southwood, 1999). It could also, however, be due to the fact that generalist caterpillar species have the ability to feed upon introduced plant species or that some Lepidoptera species are themselves introduced.

The abundance and occupancy data of caterpillar species from this study do not support the general view that Lepidoptera species in urban environments tend towards monodominance (Eremeeva \& Sushchev, 2004; Restrepo and Halffter, 2013). Other studies of urban lepidoptera have found communities to be far less diverse (Ockinger et al., 2009; Restrepo and Halffter, 2013; Sing et al., 2016), although generally on much larger, less variable sites. It must be noted, however, that the small number of individuals relative to the number of species might reflect the fact that sampling was not able to fully capture the caterpillar assemblages on sites, and should be conducted over a longer timeframe. Wolda et al. (1994), however, observed that butterflies found in the city tended to be either 'accidental' species, originating from the surrounding matrix, or 'tramp' species that could utilise the resources available in urban areas. Although we can infer some breeding site selection rather than just 'accidental' presence; it could still be the case that while a few butterflies and moths were originating from nearby areas to lay their eggs on roundabouts, adult populations existed mainly in the surrounding matrix. It does not negate the fact, however, that roundabouts, could provide 'stepping stones' in the landscape, facilitating dispersal to larger urban greenspace (Bonebrake and Cooper, 2014). Thus, improving the habitat quality of roundabouts could increase their dispersal utility to Lepidoptera species. The similarity of the number of individuals and species also means that the responses of species richness and caterpillar abundance to habitat variables are likely to be similar and may partly reflect the response of one another. Further study is needed to investigate the variability of caterpillar assemblages on roundabouts and disentangle the response of species richness and abundance.

Other variables, aside from tree species and density, could influence the caterpillar species richness and abundance on sites. The nature of the matrix surrounding each roundabout site, and its suitability as a habitat for lepidopteran larvae, will influence the migration of Lepidoptera onto specific sites. The connectivity of urban sites and composition of the surrounding matrix, including the extent of urbanisation, has been found to affect lepidopteran assemblages (Ockinger et al., 2009; Restrepo and Halffter 2013). Local habitat variables, however, have been shown to exert a relatively important effect on urban Lepidoptera in studies of the comparative effect of habitat quality and landscape (Ockinger, 2009). Rickman \& Connor (2003), found that in fragmented habitat the influence of patch attributes is greater than the influence of its surroundings.

The identity of tree species will also influence the insect species diversity. For two tree genera found on the sites, 284 insect species are associated with Quercus and only 31 with Tilia (Southwood, 1961). Macrolepidoptera specifically have 106 species associated with two species of Quercus and 31 with two species of Tilia (Kennedy \& Southwood, 1984). Plant architecture and age are similarly important, as more species will be associated with larger, more structurally diverse and older trees (Lawton, 1983). Helden \& Leather (2004), however, state that due to the fact that trees show large variability in the number of insect species they support, it is likely that tree species number is more important than architecture or age. 
Lepidopteran species display different responses to urbanisation; some appear to be completely absent from urban areas and some, such as Pieris brassicae, to be urban exploiters (Wood \& Pullin, 2002; Kaiser et al., 2016). Further study is needed to explore Lepidoptera species-specific responses to habitat and tree vegetation characteristics of urban roundabouts to truly assess their conservation potential. If caterpillar species that are found most commonly on roundabouts are pests or invasive species it will reduce their conservation value. On the other hand, if roundabouts are used by urban exploiters or specialists, it may increase the probability that they can maintain viable populations. Finally, the ability of urban greenspace to harbour rare species has been demonstrated (Tam et al., 2016); if roundabouts are suitable habitats to support species of conservation interest it will further raise their potential conservation value.

The possibility that roundabouts may act as population sinks could also be investigated with further study. Observations of the prevalence of adult Lepidoptera on roundabouts could provide information about adult mortality or the ratio of caterpillars to adults, and thus whether a roundabout is acting as a population sink by reducing adult or larval survival (Saarinen et al. 2005). As butterfly and moth species are often weak, low fliers, the act of crossing roads may substantially increase mortality, which would be further exacerbated if roundabouts were attractive Lepidoptera habitat (Di Mauro, 2007). Ries et al. (2001), however, found that although butterfly mortality was high on roads, it was low compared with other factors. Additionally, Angold (2006) found dispersal not to be a limiting factor for butterfly populations in urban areas, habitat quality being more important. Dispersal may be more important, however, on smaller urban site such as roundabouts.

In order to increase species richness and the abundance of tree feeding caterpillars on roundabouts, and thus potentially the diversity and abundance of butterflies and moths in urban areas, several conservation management schemes can be suggested. Increasing habitat richness and tree species richness may help increase the species richness and abundance of caterpillars. This said, however, the habitat requirements of other groups, such as grassland and meadow Lepidoptera, should also be taken into account when designing roundabout habitat (Saarinen, 2005). As well as having direct effects on Lepidoptera assemblages, human communities may benefit from more species and greater abundance of butterflies. Similarly, increasing arboreal caterpillar abundance can have positive effects on the success of certain bird species such as blue tits, Parus caeruleus, further increasing amenity value of urban green space (Tremblay, 2005). Tree diversity and abundance on Bracknell roundabouts has been shown to have a positive effect on the number of insectivorous birds through providing the additional food resources of Hemiptera feeding on the trees (Helden et al., 2012).

\section{References}

Angold, P.G., sadler, J.P., Hill, M.O., Pullin, A., Rushton, S., Austin, K., Smal, E., Wood, B., Wadsworth, R., Sanderson, R. \& Thompson, K. (2006) Biodiversity in urban habitat patches. Sci Tot Env 360: 196-204

Arrhenius, O. (1921) Species and area J Anim Ecol 9: 95-99 
Blair, R.B. (1999) Birds and butterflies along an urban gradient: surrogate taxa for assessing biodiversity Ecol Appl 9: 164-170

Blair, R.B. \& Launer, A.E. (1997) Butterfly diversity and human land use: species assemblages along an urban gradient. Biol Conserv 8: 113-125

Bonebrake T.C., Cooper D.S. (2014) A Hollywood drama of butterfly extirpation and persistence over a century of urbanization. J Insect Conserv 18: 683-692

Brown, K.S. \& Freitas, A.V.L. (2002) Butterfly communities of urban forest fragments in Campinas, Sao Paulo, Brazil: Structure, instability, environmental correlates, and conservation. J Ins Conserv 6: 217-231

Carter, D.J. \& Hargreaves, B. (1986) Field Guide for Caterpillars of Britain and Europe. HarperCollins, London.

Chinery, M. (1976) A Field Guide to the Insects of Britain and Northern Europe. Collins, London

Denys, C. \& Schmidt, H. (1998) Insect communities on experimental mugwort (Artemisia vulgaris L.) plots along an urban gradient. Oecologia 113: 269-277

Di Mauro, D., Dietz, T. \& Rockwood, L. (2007) Determining the effect of urbanization on generalist butterfly species diversity in butterfly gardens, Urban Ecosyst 10: 427-439

Eremeeva, N.I. \& Sushchev (2005) Stuctural changes in the fauna of pollinating insects in urban landscape Russ J Ecol 36: 259-265

Evans, K., Newson, S.E. \& Gaston, K.J. (2009) Habitat influences on urban avian assemblages. Ibis 151: $19-39$

Faeth, S.H. \& Kane, T.C. (1978) Urban Biogeography - city parks as Islands for Diptera and Coleoptera. Oecologia 32: 127-133

Fuller, R.M., Smith, G.M., Sanderson, J.M., Hill, R.A., Thomson, A.G., Cox, R., Brown, N.J., Clarke, R.T., Rothery, P. \& Gerard, F.F. (2002) Countryside Survey 2000 Module 7. Land Cover Map 2000. Final Report CSLCM/Final. Monks Wood, UK: Centre for Ecology and Hydrology.

Giuliano, W.M., Accamando, W.K. \& McAdams, E.J. (2004) Lepidoptera-habitat relationships in urban parks. Urban Ecosyst 7: 361-370

Goddard, M.A., Dougill, A.J. and Benton, T.G. (2009) Scaling up from gardens: biodiversity conservation in urban environments. Trends Ecol Evol 25: 90-98

Hardy, P.B. \& Dennis, R.L.H (1999) The impact of urban development on butterflies within a city region. Biodivers Conserv 8: 1261-1279

Helden, A.J. \& Leather, S.R. (2004) Biodiversity on urban roundabouts - Hemiptera, management and the species-area relationship Basic \& Appl Ecol 5: 367-377 
Helden, A.J. \& Leather, S.R. (2005) The Hemiptera of Bracknell as an example of biodiversity within an urban environment. Br J Ent \& Nat Hist 18: 233-252.

Helden, A.J., Stamp, G.C., \& Leather, S.R. (2012) Urban biodiversity: comparison of insect assembalges on native and non-native trees. Urban Ecosyst 15: 611-624

Ihaka, R., \& Gentleman, R. (1996) R: A language for data Analysis and graphics. J Comp \& Graph Stats 5: 299-314

Jones, E.L. \& Leather, S.R. (2012) Invertebrates in urban areas: a review. Eur J Entomol 109: 463478

Kaiser, A., Merckx, T. and Van Dyck, H. (2016) The Urban Heat Island and its spatial scale dependente impact on survival and development in butterflies of different thermal sensitivity. Ecol Evol 6: 4129-4140

Kennedy, C.E.J., \& Southwood, T.R.E. (1984) The number of species of insects associated with British trees: A re-analysis. J Anim Ecol 53: 455-478

Kelly, C.K. \& Southwood, T.R.E (1984) Species richness and resource availability: a phylogenetic analysis of insects associated with trees PNAS 96: 8013-8016

Lawton, J.H. (1983) Plant architecture and the diversity of phytophagous insects. Ann Rev Ent 28: 23-39

Leather, S.R. (1991) Feeding specialisation and host distribution of British and Finnish Prunus feeding macrolepidoptera. Oikos 60: 40-48.

Leather, S.R. \& Helden, A.J. (2005) Roundabouts: our neglected nature reserves? Biologist 52: 102106.

Maller C., Townsend M., Pryor A., Brown P., Leger L.S.T. (2005) Healthy nature healthy people : “ contact with nature " as an upstream health promotion intervention for populations. Health Promot Int 21: 4554

Mitchell, A, \& Wilkinson, J. (1988) Trees of Britain and Northern Europe. HarperCollins, London.

Niemela, J. (1999) Ecology and urban planning. Biodivers Conserv. 8: 119-131

Ockinger, E., Dannestam, A. And Smitth, H.G.(2009) The importance of fragmentation and habitat quality of urban grasslands for butterfly diversity. Landsc Urban Plan 93: 31-37

Porter, J. (1997) The Colour Identification Guide to Caterpillars of the British Isles. Penguin Books, London.

Restrepo, L.R. and Halffter, G. (2013) Butterfly diversity in a regional urbanization mosaic in two Mexican cities. Landsc Urban Plan 115: 39-48

Rickman, J.K. \& Connor, E.F. (2003) The effect of urbanization on the quality of remnant habitats for leaf-mining Lepidoptera on Quercus agrifolia. Ecogr 26: 777-789 
Ries, L., Debinski, D.M. \& Wieland, M.L (2001) Conservation value of Roadside Prairie restoration to butterfly communities. Conserv Biol 15: 401-411.

Saarinen, K., Valtonen, A., Jantunen, J. \& Saarnio, S. (2005) Butterflies and diurnal moths along road verges: Doess road type affect diversity and abundance? Biol Conserv 123: 503-412.

Scheffers, B.R., Edwards, D.P., Diesmos, A., Williams, S.E. and Evans, T.A. (2014) Microhabitats reduce animal's exposure to climate extremes. Glob Change Biol 20: 495-503

Schmidt, B.C. \& Roland, J. (2006) Moth diversity in a fragmented habitat: importance of functional groups and landscape scale in the boreal forest. Ann Ent Soc Am 99: 1110-1120.

Skinner (2000) Colour Identification Guide to Moths of the British Isles (Macrolepidoptera)

Sing, K-W., Juosh, W.F.A., Hashim, N.R. and Wilson, J-J. (2016) Urban parks: refuges for tropical butterflies in Southeast Asia? Urban Ecosyst 19: 1131-1147

Southwood, T.R.E. (1961) The number of species of insect associated with various trees. J Anim Ecol 30: 1-8.

Takami, Y., Koshio, C., Ishii, M., Fujii, H., Hidaka, T. \& Shimizu, I. (2004) Genetic diversity and structure of urban populations of Pieris butterflies assessed using amplified fragment length polymorphism. Mol Ecol 13: 245-258

Tam, C.T. and Bonebrake, T.C. (2016) Butterfly diversity, habitat and vegetation usage in Hong Kong urban parks. Urban Ecosyst 19: 721-733

Tolman, T. \& Lewington, R. (2004) Field Guide for Butterflies of Britain and Europe. HarperCollins, London.

Tremblay, I., Thomas, D., Blondel, J., Perret, P. \& Lambrecht, M.M. (2005) The effect of habitat quality and forgaing patterns on provisioning rate and nestling growth in Corsican Blue Tits Parus caeruleus. Ibis 147: 17-24

UN (2008). World Urbanization Prospects: the 2007 Revision. New York: United Nations.

Van Dyck, H., Van Strien, A.J., Maes, D. \& Van Sway, C.A.M. (2009) Declines in common, widespread butterflies in a landscape under intense human use. Conserv Biol 23: 957-965

Whitmore, C., Crouch, T. E., \& Slotow, R. H. (2002) Conservation of biodiversity in urban environments: Invertebrates on structurally enhanced road islands. Afr Ent 10: 113-126.

Wolda, H., Marek, J., Spitzer, K. \& Noval, I. (1994) Diversity and variability of Lepidoptera populations in urban Brno, Czech Republic. J Eur Entomol 91: 213-226.

Wood, B.C. \& Pullin, A.S. (2002) Persistence of species in a fragmented urban landscape: the importance of dispersal ability and habitat availability for grassland butterflies. Biodivers \& Conserv 11: 1451-1468. 
Zapparoli, M. (1997) Urban development and insect biodiversity of the Rome area, Italy. Landsc Urban Plan 38: 77-86.

Table 1. The locations and names of the roundabouts for which the habitat and species data was collected.

\begin{tabular}{|l|l|l|l|}
\hline Site & Site name & $\begin{array}{l}\text { Grid } \\
\text { reference }\end{array}$ & Area $\mathrm{m}^{2}$ \\
\hline 2 & $\begin{array}{l}\text { Running Horse } \\
\text { roundabout }\end{array}$ & SU883691 & 1403.38 \\
\hline 3 & $\begin{array}{l}\text { Eastern Road } \\
\text { roundabout }\end{array}$ & SU880693 & 2068.09 \\
\hline 4 & $\begin{array}{l}\text { Metereological office } \\
\text { roundabout }\end{array}$ & SU874695 & 5369.3 \\
\hline 5 & $\begin{array}{l}\text { Bracknell station } \\
\text { roundabout }\end{array}$ & SU871689 & 487.49 \\
\hline 6 & $\begin{array}{l}\text { Broad Lane } \\
\text { roundabout }\end{array}$ & SU871685 & 3062.44 \\
\hline 7 & Bill Hill & SU869684 & 25714.3 \\
\hline 8 & $\begin{array}{l}\text { Bracknell Sports } \\
\text { Centre roundabout }\end{array}$ & SU873677 & 2628.76 \\
\hline 10 & Mill Pond roundabout & SU860678 & 1615.98 \\
\hline 11 & Mill Pond park & SU859681 & 98524.0 \\
\hline 12 & Mill Lane slip road & SU858683 & 5786.81 \\
\hline 14 & Twin bridges \\
roundabout south & SU863690 & 2682.84 \\
\hline Twin bridges & SU863691 & 2230.34 \\
\hline & & & 1 \\
\hline 15 & & & \\
\hline
\end{tabular}




\begin{tabular}{|l|l|l|l|}
\hline & roundabout north & & \\
\hline 17 & 3 M roundabout & SU867695 & 4677.18 \\
\hline 18 & Arlington roundabout & SU864695 & 1005.74 \\
\hline
\end{tabular}

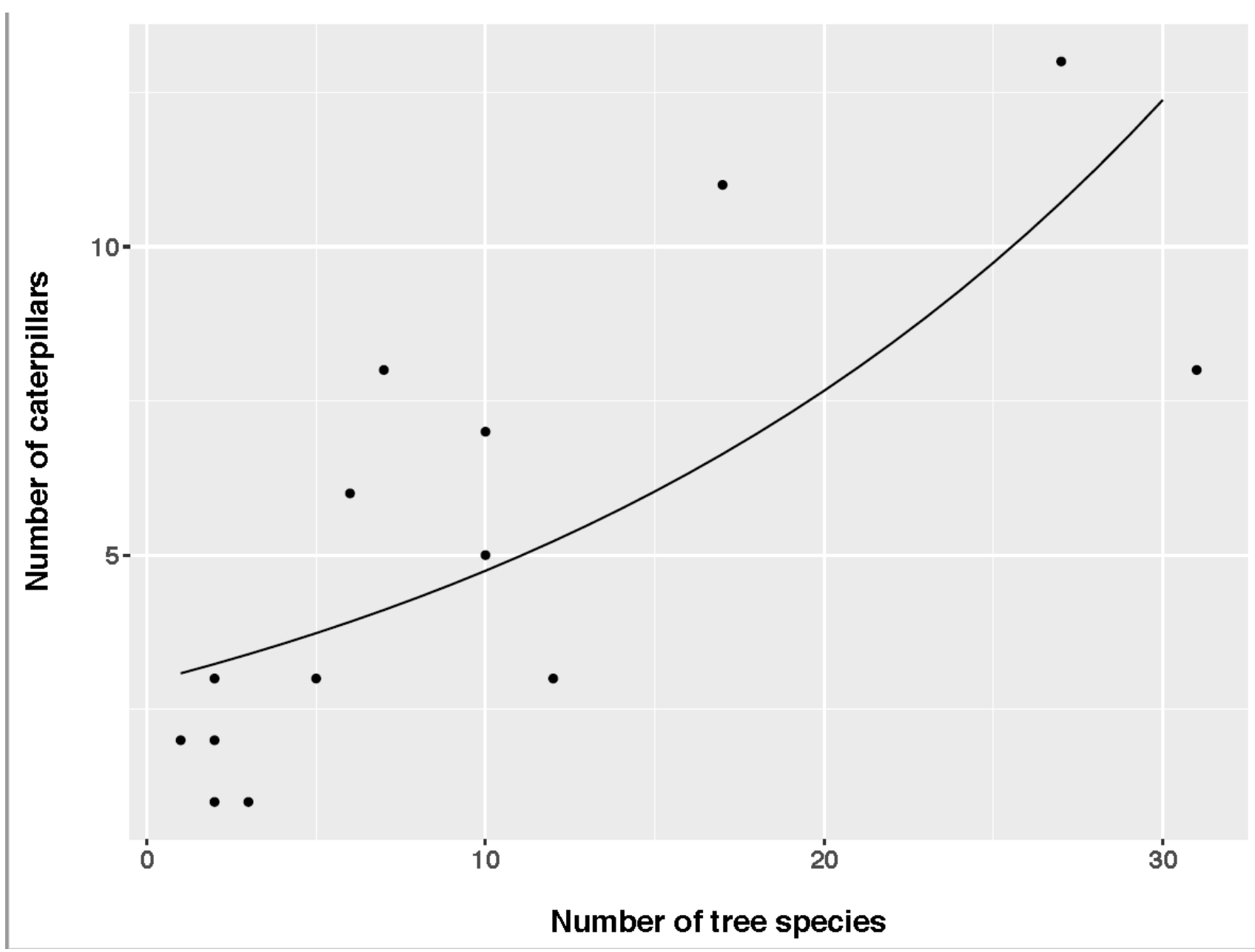

Fig 1. Relationship between the number of tree species present on a roundabout and the overall abundance of caterpillars. 


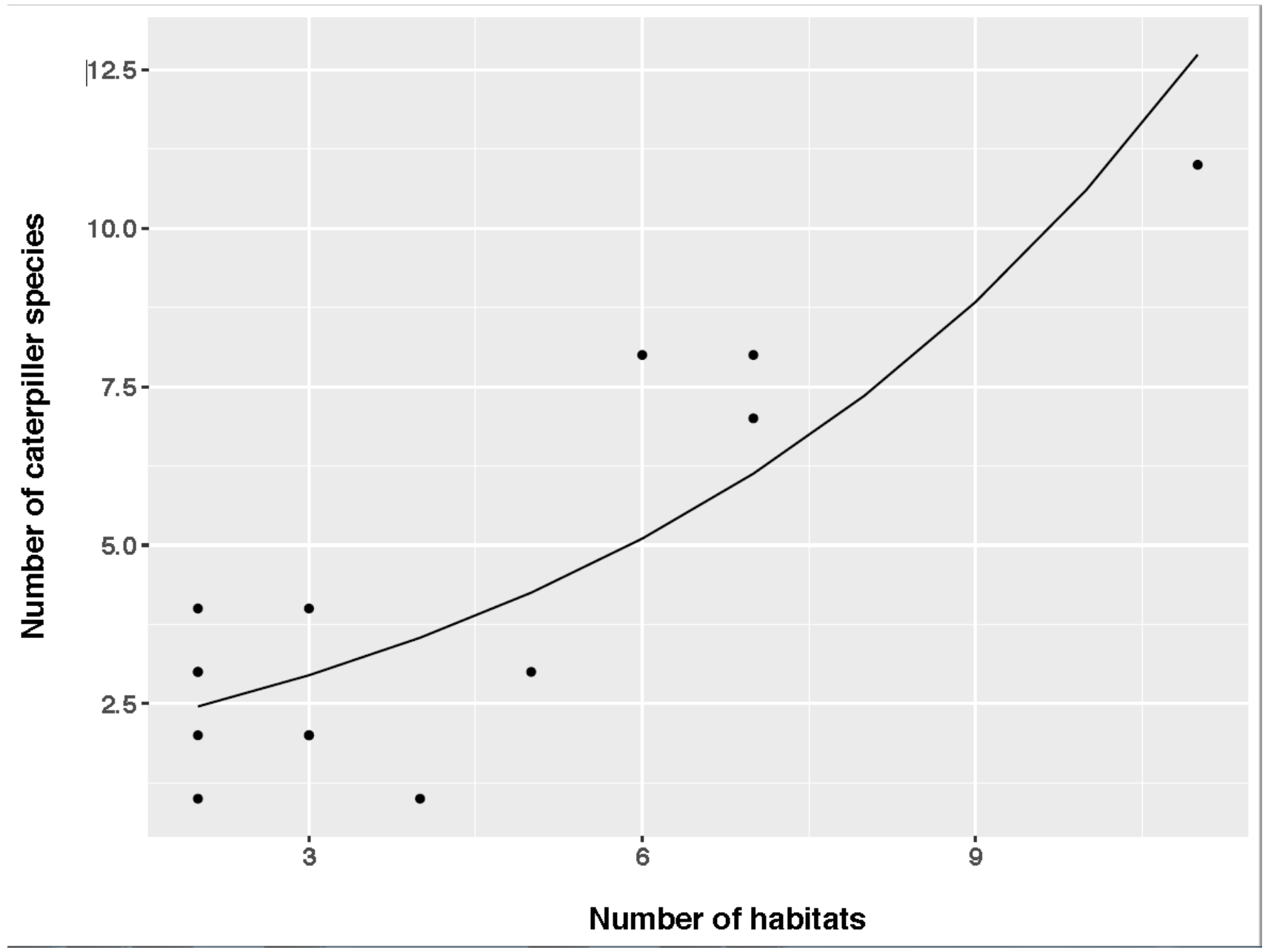

Fig 2. Relationship between habitat diversity and the number of caterpillar species present on Bracknell roundabouts. 